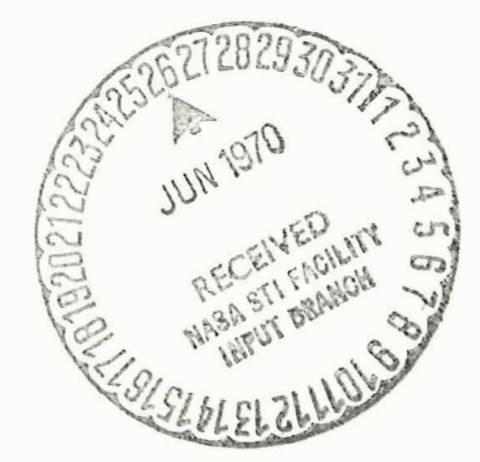

by R. C. Hendricks and K. J. Baumeister

Lewis Research Center

Cleveland, Ohio

TECHNICAL PAPER proposed for presentation at

Cryogenic Engineering Conference

Bolder, Colorado, June 17-19, 1970 
LIQUID OR SOLID ON LIQUID IN LEIDENFROST FILM BOILING

by R. C. Hendricks and K. J. Baumeister

Lewis Research Center

Cleveland, Ohio

TECHNICAL PAPER proposed for presentation at

Cryogenic Engineering Conference

Boulder, Colorado, June 17-19, 1970

NATIONAL AERONAUTICS AND SPACE ADMINISTRATION 


\section{LIQUID OR SOLID ON LIQUID IN LEIDENFROST FILM BOILING}

by $R$. C. Hendricks and $\mathrm{K}$. J。 Baumeister

Lewis Research Center

National Aeronautics and Space Administration

Cleveland, Ohio

\section{ABSTRACT}

A hydrodynamic model is postulated for a small, liquid or solid sphere film boiling on a saturated cryogenic liquid surface, such as may occur in propellant spillage accidents and in the preparation and preservation of some biological species (e.g., blood and enzymes). The momentum and energy equations are solved analytically to predict the velocity and temperature fields in the vapor film beneath the sphere. This leads to a heattransfer coefficient of the form

$$
\mathrm{h}_{\mathrm{d}}=\frac{\mathrm{k}}{\mathrm{R}}+\left[\frac{2}{9} \frac{\mathrm{k}^{3} \rho_{\mathrm{d}} \rho \mathrm{g} \lambda^{*}}{\mathrm{R} \mu\left(\mathrm{T}_{\mathrm{d}}-\mathrm{T}_{\mathrm{s}}\right) \mathrm{f}\left(\theta^{*}\right)}\right]^{1 / 4}
$$

where $\mathrm{k}$ is the thermal conductivity of the vapor, $\rho_{\mathrm{d}}$ the density of the sphere, $\rho$ the density of the vapor, $\lambda^{*}$ the modified latent heat, $\mathrm{R}$ the radius of the sphere, $\mu$ the vapor viscosity, $T_{d}$ and $T_{S}$ the temperature of the sphere and the liquid, respectively, and $f\left(\theta^{*}\right)$ a function which depends on the characteristics of the sphere and the supporting fluid. The values $f(\theta$ * $)$ and dimensionless forms of the heat-transfer solutions are given in the paper. This expression for the heat-transfer coefficient combined with a thermal balance predicts the time a hot sphere will remain 
levitated in Leidenfrost Iim bolling when placed on a cryogenic liquid. The agreement between experimental and predicted times is fair.

A motion plcture supplement demonstrating the phenomenon is avariable upon request from the authors.

\section{INTRODUCTION}

Film-boiling heat transfer between two iiquids at different temperatures has been under extensive investigation recently in consideration of propellant spillage accidents (ref,1). If liquid propellants spill accidently during teststand or launching operations, a catastrophic expolsion resulting from the detonation of the fuel and oxidizer is possible. In particular, a number of experiments (ref, 1) have been performed invoiving the mixing of small kerosene spheres in liquid oxygen. When small kerosene spheres are dispersed in a matrix of liquid oxygen, the sensible heat of the kerosene spheres is drained off and vaporizes the liquid oxygen, thereby forming a film of oxygen vapor around the sphere. In film bolling, the vaporization rates are one or more orders of magnitude less than those of peak-nucleate boiling. In nucleate boiling, extreme turbulence and mixing will occur because of the large amount of vapor sporadically generated at the interface. On the other hand, film boiling is a relatively quiescent phenomena, and as such can have a significant damping effect on the mixtures explosive potential. The encapsulation of the liquid sphere (as it freezes), as shown herein, can also provide significant dampening。

The liquid-liquid film bolling phenomenon is also of interest purely from stability considerations. In this case, a liquid sphere with a higher specific gravity floats upon a cryogenic liquid of lower specific gravity while film 
boiling is taking place. The sphere usually freezes and continues to float (solid-liquid film boiling) then suddenly at the transition from film boiling to nucleate boiling, the vapor blanket surrounding the sphere disappears. Then the sphere sinks beneath the liquid and falls to the bottom of the pool.

This paper considers two aspects of this liquid-liquid or solid-liquid film-boiling problem. First, a hydrodynamic model is postulated for a small, spherical, liquid drop film boiling on a cryogenic surface. The conservation equations of momentum and energy are solved analytically to predict the velocity and temperature fields, and a simple theoretical correlation for the heat-transfer coefficient is presented. Details of the solution are presented in reference 4.

Secondly, a heat balance is performed on the sphere, which leads to a correlation equation for predicting the time required for a liquid sphere to cool from room temperature to its freezing point and then to the temperature at which boiling ceases: liquid subcooling was neglected. Theory is checked with experiment by placing water spheres on liquid nitrogen and comparing the experimental and theoretically predicted times for the sphere to "float". Fair agreement was found.

A motion picture supplement demonstrating the phenomena is available from the authors upon request.

\section{BASIC MODEL AND EQUATIONS}

Consider the film model depicted in figure 1. This model appears to fit the physical case of a solid or liquid sphere "floating" on a second liquid (solid-liquid and liquid-liquid film boiling)。 For example, drops of water floating on a sea of liquid nitrogen. There is, of course, no reason to limit 
the model to liquid spheres or cryogenic fluids. Slush and small solid materials could also be utilized on any liquid provided the proper temperature difference and buoyancy criteria are maintained.

The model may be applied either to the case where the sensible heat of the floating sphere evaporates the encompassing liquid or where the sensible heat of the encompassing liquid evaporates the floating sphere, (e.g., liquid nitrogen sphere on water)。For simplicity, it is assumed throughout the remainder of this paper that the supporting fluid evaporates at the interface. Physically, for the experimental results considered herein, the heat passes from the warmer spherical drop and evaporates the fluid material beneath it, thereby forming a supporting vapor layer under the sphere. The vapor layer is, in turn, supported by the interface. Surface tension, density ratio, buoyancy, surface curvature, and the ${ }^{81}$ nonwetting $^{: B}$ character of the interface play an important role in determining whether the interface is strong enough to support the sphere. During the evaporative, or film-boiling, process the temperature of the sphere decreases until it coincides with the Leidenfrost temperature of the liquid. At this time film boiling ceases, and transition boiling quickly followed by nucleate boiling begins. The vapor layer beneath the sphere no longer exists; rather, small nucleate bubbles form in the sites on the solid (liquid) sphere. Thus, because there is no longer a supporting vapor gap, the sphere sinks beneath the surface and falls to the bottom.

The following assumptions are made in developing the model:

(1) Evaporation and internal circulation of the liquid sphere and radiation are considered small. 
(2) The model has complete symmetry with respect to the $\Phi$ coordinate.

(3) The flow of vapor is considered laminar and incompressible; and the inertia terms in the Navier-Stokes equations are neglected.(see refs. 2 and 4$)$.

(4) The velocity and temperature profiles are assumed to be in steady state and the vapor gap thickness to be a constant.

(5) At any instant of time, the sphere is at an average temperature $T_{d}$, and the evaporating liquid is assumed to be at the saturation temperature $T_{S}$. The properties of the flow field are evaluated at the film temperature $\mathrm{T}_{\mathrm{f}}=\left(\mathrm{T}_{\mathrm{d}}+\mathrm{T}_{\mathrm{S}}\right) / 2$ and are considered to be constant. This assumption has worked quite well, (e.g., ref. 2).

(6) The major mode of heat transport is by conduction (see refs. 2 and 4). Thus, it is assumed that

$$
\frac{\mathrm{V}_{\theta}}{\mathrm{r}} \frac{\partial \mathrm{T}}{\partial \theta}<\mathrm{V}_{\mathrm{r}} \frac{\partial \mathrm{T}}{\partial \mathrm{r}} \ll \frac{\frac{\mathrm{k}}{\rho \mathrm{C}_{\mathrm{p}}}}{\mathrm{r}^{2}} \frac{\partial}{\partial \mathrm{r}}\left(\mathrm{r}^{2} \frac{\partial \mathrm{T}}{\partial \mathrm{r}}\right)
$$

(i.e., the convection terms may be neglected). Furthermore polar conduction is less than radial conduction, thus

$$
\frac{1}{\mathrm{r}^{2} \sin \theta} \frac{\partial}{\partial \theta}\left(\sin \theta \frac{\partial \mathrm{T}}{\partial \theta}\right)<\frac{1}{\mathrm{r}^{2}} \frac{\partial}{\partial \mathrm{r}}\left(\mathrm{r}^{2} \frac{\partial \mathrm{T}}{\partial \mathrm{r}}\right)
$$

(7) Heat transport within the sphere is by conduction alone. With cooling at the lower surface there should be no instabilities or ensuing cellular motion. Supercooling during freezing is neglected. 
(8) The supporting liquid is at the saturation temperature. Thus, with assumption 7, all the heat reaching the liquid produces vapor.

The governing equations are as follow (ref. 3):

1. Momentum

$$
\begin{gathered}
0=-\frac{\mathrm{g}_{\mathrm{c}}}{\rho} \frac{\partial \mathrm{P}}{\partial \mathrm{r}}+\nu\left(\nabla^{2} \mathrm{~V}_{\mathrm{r}}-\frac{2 \mathrm{~V}_{\mathrm{r}}}{\mathrm{r}^{2}}-\frac{2}{\mathrm{r}^{2}} \frac{\partial \mathrm{V}_{\theta}}{\partial \theta}-\frac{2 \mathrm{~V}_{\theta}}{\mathrm{r}^{2}} \cot \theta\right) \\
0=-\frac{\mathrm{g}_{\mathrm{c}}}{\rho \mathrm{r}} \frac{\partial \mathrm{P}}{\partial \theta}+\nu\left(\nabla^{2} \mathrm{~V}_{\theta}+\frac{2}{\mathrm{r}^{2}} \frac{\partial \mathrm{V}_{\mathrm{r}}}{\partial \theta}-\frac{\mathrm{V}_{\theta}}{\mathrm{r}^{2} \sin ^{2} \theta}\right)
\end{gathered}
$$

where

$$
\nabla^{2}=\frac{1}{r^{2}} \frac{\partial}{\partial r}\left(r^{2} \frac{\partial}{\partial r}\right)+\frac{1}{r^{2} \sin \theta} \frac{\partial}{\partial \theta}\left(\sin \theta \frac{\partial}{\partial \theta}\right)
$$

2. Energy

$$
0=\frac{\partial}{\partial \mathrm{r}}\left(\mathrm{r}^{2} \frac{\partial \mathrm{T}}{\partial \mathrm{r}}\right)
$$

3. Continuity

$$
0=\frac{1}{r^{2}} \frac{\partial}{\partial r}\left(r^{2} V_{r}\right)+\frac{1}{r \sin \theta} \frac{\partial}{\partial \theta}\left(V_{\theta} \sin \theta\right)
$$

The boundary conditions on the velocity and temperature fields are given in table $\mathrm{I}$, where $\theta^{*}$ is defined in figure 1 , and $\delta$ is the vapor gap thickness. 


\begin{tabular}{|l|l|l|}
\hline Drop surface & $\begin{array}{l}\mathrm{r}=\mathrm{R} \\
\theta=\theta\end{array}$ & $\begin{array}{l}\mathrm{V}_{\mathrm{r}}=0 \\
\mathrm{~V}_{\theta}=0 \\
\mathrm{~T}=\mathrm{T}_{\mathrm{d}}\end{array}$ \\
\hline $\begin{array}{l}\text { Liquid-vapor } \\
\text { interface }\end{array}$ & $\begin{array}{l}\mathrm{r}=\mathrm{R}+\delta \\
\theta=\theta\end{array}$ & $\begin{array}{l}\mathrm{V}_{\mathrm{r}}=\mathrm{V}_{\mathrm{r}}(\mathrm{R}+\delta, \theta) \\
\mathrm{V}_{\theta}=0 \\
\mathrm{~T}=\mathrm{T}_{\mathrm{S}}\end{array}$ \\
\hline $\begin{array}{l}\text { "Stagnation" } \\
\text { region }\end{array}$ & $\begin{array}{l}\mathrm{R} \leq \mathrm{r} \leq \mathrm{R}+\delta \\
\theta=0\end{array}$ & $\mathrm{~V}_{\theta}=0$ \\
\hline "Separation" & $\mathrm{r}=\mathrm{R}$ & $\mathrm{P}=\mathrm{P}_{\mathrm{O}}$ \\
region & $\theta=\theta *$ &
\end{tabular}

Table: I. - Boundary Conditions for the Floating Sphere, $\theta \leq \theta^{*}$

The boundary conditions are still incomplete at this point since $\delta$, $\mathrm{V}_{\mathrm{r}}(\mathrm{R}+\delta)$, and $\theta^{*}$ are unknowns. Hence, three additional mathematical constraints are necessary to make the problem tractable.

\section{Static Force Balance \\ (Neglecting Forces Internal to Drop)}

One additional constraint requires that the weight of the drop be balanced by the shear and pressure forces acting beneath the drop. These forces are depicted in figure 2. Summing the forces acting in the vertical direction gives

$$
\begin{aligned}
& 0=\mathrm{W}_{\mathrm{d}}-\left.\int_{0}^{2 \pi} \int_{0}^{\theta^{*}}\left(\mathrm{P} \cos \theta+\tau_{\mathrm{r} \theta} \sin \theta-\tau_{\mathrm{rr}} \cos \theta\right)\right|_{\mathrm{r}=\mathrm{R}} \mathrm{R}^{2} \sin \theta \mathrm{d} \theta \mathrm{d} \Phi \\
&+\int_{0}^{2 \pi} \int_{\pi}^{\theta^{*}} \mathrm{P}_{\mathrm{o}} \cos \theta \mathrm{R}^{2} \sin \theta \mathrm{d} \theta \mathrm{d} \Phi
\end{aligned}
$$


The last term in equation (12) represent ambient pressure force acting on the upper portion of the drop.

\section{Interface Energy Balance}

The second constraint necessary for the solution of equations (3) to (7) is the interface energy balance. Because the supporting fluid has been assumed to be at the saturation temperature (assumption 8 ), all the heat leaving the drop produces evaporation of the fluid material. Mathematically, this constraint is expressed as

$$
-\rho \lambda \mathrm{V}_{\mathrm{r}}(\mathrm{R}+\delta, \theta)=-\left.\mathrm{k} \frac{\partial \mathrm{T}}{\partial \mathrm{r}}\right|_{\mathrm{r}=\mathrm{R}+\delta}
$$

where $\lambda$ is the latent heat of vaporization and $-\left.\mathrm{k}(\partial \mathrm{T} / \partial \mathrm{r})\right|_{\mathrm{r}=\mathrm{R}+\delta}$ is the conduction heat flux to the boundary of the supporting liquid.

\section{Free Surface Pressure Head}

The third and final constraint is that the forces supporting the sphere must be transmitted and balanced by the supporting fluid interface. Here the free surface head $Z_{0}$, as shown in figure 3 must be determined from a balance of forces acting on the liquid-vapor surface membrane. The determination of $\mathrm{Z}_{\mathrm{o}}$ such that all forces are balanced and the sphere is supported also uniquely prescribes a value to $\theta^{*}$.

The solution of the governing equation is long and involved, but quite straight forward in that the number of equations now matches the number of unknowns. The derivation is given in appendix B.

The expression for the heat transfer coefficient to the sphere becomes 


$$
\mathrm{h}_{\mathrm{d}}=\frac{\mathrm{k}}{\mathrm{R}}+\left[\frac{2 \rho \rho_{\mathrm{d}} \mathrm{gk}^{3} \lambda *}{9 \mu \mathrm{R}\left(\mathrm{T}_{\mathrm{d}}-\mathrm{T}_{\mathrm{S}}\right)\left(\cos ^{2} \theta^{*}-2 \cos \theta^{*}+1\right)}\right]^{1 / 4}
$$

where the value of $\theta^{*}$ is given in figure 4 , for the optimum (most massive) levitated sphere. A first order estimate of $\theta^{*}$ for non-optimum (lighter than optimum) spheres is found in reference 5, or calculated directly from the technique in appendix $\mathrm{B}$.

\section{COMPARISON OF EXPERIMENT AND THEORY}

A simple test of the analytical model is performed using a water sphere on liquid nitrogen. At the expense of the internal energy of the water spheroid, liquid nitrogen is vaporized beneath the drop. This vapor forms the supporting cushion for the drop, which appears to "float" on the much colder nitrogen surface.

A slight amount of dye coloring was added to the water. During the freezing process, the dye color changes and continues to change until the entire drop is frozen. The frozen drop is then a hard sphere "floating" on a sea of liquid nitrogen. Its free floating state is sharply terminated at the onset of nucleate boiling, and the drop falls beneath the surface

The size of the water droplet used can be determined by measuring the residue (the hard sphere of ice) or by using a pipette. Both techniques were used. A stop clock was used to determine the elapsed time between placing the water on the nitrogen and the color change in the drop, the time for the drop to be completely frozen, and the time for the drop to fall to the bottom. The experimental results are presented in table II. 
To use the experimentally measured drop freezing times as a check on the theoretically determined heat transfer coefficient, it is necessary to determine the temperature of the drop as a function of time during freezing. There are, however, many facets of the freezing problem that we do not understand. For example, the convective heat transfer coefficient from the top of the droplet as well as internal convection are unknown; if supercooling occurs (up to $T_{d}-T_{i c e}=40^{\circ} \mathrm{K}$ is possible), the solid will not form at the freezing temperature which completely alters a heat balance; the compressive effects of freezing on the interface freezing temperature and interface growth rate are not known; the effects of cracks, ice "worms", and the $4^{\mathrm{O}} \mathrm{C}$ inversion point are also unknown; to what extent does eccentric cooling and freezing alter a concentric drop freezing analysis ?; the effect of a pseudo-steady analysis as compared to a complete transient analysis is difficult to assess; to what extent is the metastable Leidenf rost phenomenon influencing the results? If a droplet followed the metastable Leidenfrost Line (ref。6) then floating times would be greatly extended.

Each of these unknowns constitutes a report in itself. As a first order approximation to the actual problem, two simplified models will be used.

The first model, called the pseudo-steady state model, takes into account thermal gradients in the freezing sphere. The calculated temperature-time history for this model is given by the lower curve shown in figure 5. The derivation for this model is given in reference 4 .

The second model, called the Newtonian model, assumes that no thermal gradients exist in the drop. This is analogous to the classical 
Newtonian cooling problem. This model will now be considered. First, the time required for the drop to cool to the freezing temperature, $t_{\text {sen }}$, must be calculated. Next, the time required for the heat of fusion to be removed, $t_{i c e}$, must be calculated. Finally, the time for the drop to cool to the transition-nucleate boiling temperature (Leidenfrost point) is calculated.

In calculating $t_{\text {sen }}$ for the Newtonian model, the surface of the water droplet is assumed to be at $0^{\circ} \mathrm{C}$ and to remain at that temperature until the remainder of the drop reaches $0^{\circ} \mathrm{C}$. The sensible cooling time can be found from an energy balance

$$
t_{\text {sen }}=\frac{m_{d} C_{p, d}\left(T_{d o}-T_{s}\right)}{(\bar{h} A)_{d}\left(T_{i c e}-T_{s}\right)}
$$

where $\bar{h}$ is determined by the fraction of the surface in film boiling that in natural convection

$$
\overline{\mathrm{h}}=\mathrm{h}_{\mathrm{d}}\left(1-\cos \theta^{*}\right)+\mathrm{h}, \mathrm{n} \cdot \mathrm{c} \cdot\left(1+\cos \theta^{*}\right)
$$

Experimentally, the natural convection coefficient, h.n.c., was determined to be

$$
\mathrm{Nu}=\frac{\mathrm{h} \cdot \mathrm{h} \cdot \mathrm{c} \cdot \mathrm{R}}{\mathrm{k}}=10
$$

and the film boiling heat transfer coefficient, $h_{d}$, is given by equation (14)。 For a 0.6 centimeter diameter water drop in nitrogen, the value of $t_{\text {sen }}$ is 4.2 seconds, as shown in figure 5 . 
The time required to freeze the entire sphere, isothermally, can be calculated in the same manner only $C_{p, d}\left(T_{d, o}-T_{S}\right)$ is replaced by $\gamma$, the latent heat of fusion, that is

$$
t_{\text {ice }}=\frac{m_{d} \gamma}{(\bar{h} A)_{d}\left(T_{i c e}-T_{s}\right)}
$$

For the 0.61 centimeter water drop on nitrogen, the value of $t_{\text {ice }}$ was 12. 5 seconds. This is represented by the horizontal line shown in figure 5 . Once the entire sphere has turned to ice, the solid drop will lose its sensible, energy and cool to the temperature of the supporting liquid. The sensible cooling time can be found from an energy balance on the drop of the form

$$
\overline{\mathrm{h}}_{\mathrm{d}} \mathrm{A}\left(\mathrm{T}_{\mathrm{d}}-\mathrm{T}_{\mathbf{s}}\right)=-(\rho \mathrm{C})_{\mathrm{ice}} \mathrm{V} \frac{\partial\left(\mathrm{T}_{\mathrm{d}}-\mathrm{T}_{\mathrm{s}}\right)}{\partial \tau}
$$

where

$$
\tau=t-\left(t_{\text {sen }}+t_{\text {ice }}\right)
$$

and at $\tau=0$, the surface temperature $T(R)$ is taken as the freezing temperature $T_{i c e}$. The solution of equation (19) for the time $\tau$, assuming that $\bar{h}_{d}$ varies little with temperature, ${ }^{*}$ becomes

$$
\because \tau=+\frac{R(\rho \mathrm{C})_{\text {ice }}}{3 \overline{\mathrm{h}}_{\mathrm{d}}} \ln \left|\frac{\mathrm{T}_{\mathrm{d}}-\mathrm{T}_{\mathrm{S}}}{\mathrm{T}_{\text {ice }}-\mathrm{T}_{\mathrm{S}}}\right|
$$

*A good assumption except near the Leidenfrost temperature. 
Thus, the time for a drop to freeze to some temperature beneath its freezing point is

$$
t=t_{\text {sen }}+t_{i c e}+\frac{R(\rho C)_{i c e}}{3 \bar{h}_{d}} \ln \left|\frac{T_{i c e}-T_{S}}{T_{d}-T_{S}}\right|
$$

From this equation, the temperature fall off shown by the upper curve in figure 5 is predicted.

As mentioned earlier, as the free floating drop cools and its outside surface temperature approaches the saturation temperature, film boiling will cease and transition-nucleate boiling will begin. At the onset of transition-nucleate boiling, the drop is wetted and sinks. The temperature at which this transition occurs is called the Leidenfrost temperature.

The Leidenfrost temperature of an ice-nitrogen combination is required. At present, there is no available data from which to estimate this Leidenfrost temperature. Consequently, an estimate of the ice-nitrogen Leidenfrost point is made from the data shown in figure 6 .

First, the dimensionless Leidenfrost temperature difference ${ }^{\theta}{ }_{L}$ for smooth or rough surfaces, shown in figure 6 , is assumed to vary linearly as a function of the natural logarithm of $\left(\beta / \beta_{\text {st }}\right)$. The $\beta$ represents a measure of how easily energy can be transported to a metallic surface. The variation of $\beta$ with surface roughness has not yet been assessed and the superposition principle with be applied using the surface roughness data of Cumo et al。(ref。7)。Cumo et al。 (ref.7) found the Leidenfrost temperature difference to be 27 percent higher on a rough surface as compared to a smooth surface. Thus the upper curve of figure 6 represents an estimate 
of how the effects of surface roughness could alter this Leidenfrost temperature. The surface of the freezing water drop with its crystalline protrusions would be a rough surface. It must be emphasized that this is only a first order estimate. The data and lines shown in figure 6 do not take into account property variations of the liquid, only the metallic surface properties are considered. For ice, the ratio of $\beta_{\mathrm{ice}} / \beta_{\mathrm{st}}$ is 13.7 . Consequently, the Leidenfrost temperature difference for ice, a rough surface, on nitrogen will be approximately 2.4 times the value measured for water on steel, or about $126 \mathrm{~K}^{*}$ as is illustrated by the horizontal line labeled $\mathrm{T}_{\mathrm{L}}$ in figure 5 . The surface temperature of the 0.61 centimeter water drop falls to this value in 29.2 seconds, at which time transition-nucleate boiling begins and the drop falls beneath the surface. Thus, the theory is seen to be in reasonable agreement with the data range illustrated by the cross hatched section of figure 5. The interface configuration used in this calculation is illustrated in figure 7 .

\section{Vaporization Rate}

Continuity at the interface requires that

$$
\left.\rho \mathrm{V}_{\mathrm{r}} \mathrm{A}\right|_{\zeta=\varphi}=\left.\rho \frac{\mathrm{dv}}{\mathrm{dt}}\right|_{\zeta=\varphi}=\frac{\mathrm{dM}}{\mathrm{dt}}
$$

Changing to dimensionless form and substituting equation (B30) and (B31), the vaporization rate may be expressed in terms of the vapor gap thickness, $\Delta$, and $\theta^{*}$; (see also eq. (B44)).

*Ref. 8 gives a Leidenfrost temperature difference, $T_{L}-T_{S}=15 \mathrm{~K}$, and ref. 9 gives $33 \mathrm{~K}$. Therefore, the corrected Leidenfrost temperature could range from 113 to $151 \mathrm{~K}$ with times of 34.2 and $23.5 \mathrm{sec}$ (see also fig. 5)。 


$$
\frac{\mathrm{dm}}{\mathrm{dt}}=\left(-1+\frac{1}{\Delta}\right)\left(\frac{1-\cos \theta^{*}}{2}\right)=\left(\frac{\mathrm{h}_{\mathrm{I}} \mathrm{R}}{\mathrm{k}}\right)\left(\frac{1-\cos \theta^{*}}{2}\right)
$$

where

$$
\mathrm{m}=\frac{\mathrm{M}}{4 \pi \mathrm{R} \mu \mathrm{S}}
$$

Equation (23) may also be formed from the interface energy balance as

$$
\begin{aligned}
\frac{\mathrm{dM}}{\mathrm{dt}} & =\frac{\mathrm{h}_{\mathrm{I} \mathrm{A} \Delta \mathrm{T}}}{\lambda}=\frac{4 \pi \mathrm{R}^{2} \Delta \mathrm{T}}{\lambda}\left(\frac{1-\cos \theta *}{2}\right) \mathrm{h}_{\mathrm{I}} \\
& =(4 \pi \mathrm{R} \mu)\left(\frac{\mathrm{k}}{\mu \mathrm{C}_{\mathrm{p}}}\right)\left(\frac{\mathrm{C}_{\mathrm{p}} \Delta \mathrm{T}}{\lambda}\right)\left(\frac{1-\cos \theta^{*}}{2}\right)\left(\frac{\mathrm{h}_{\mathrm{I}} \mathrm{R}}{\mathrm{k}}\right)
\end{aligned}
$$

If $\lambda$ is replaced by $\lambda^{*}$, then equations (25) and (24) are equivalent. For the 0.6 centimeter diameter sphere, evaluating properties at $286 \mathrm{~K}$, where $\mathrm{h}_{\mathrm{I}}=0.0155$ watt per square centimeter per second, the vaporization rate is

$$
\frac{\mathrm{dM}}{\mathrm{dt}}=0.013 \mathrm{gm} / \mathrm{sec}
$$

A crude comparison of the vapor generation rate at peak-nucleate boiling with film boiling near the Leidenfrost point gives a upper limit to the ratio of vaporization rates for our example

$$
\frac{\left.\frac{d M}{d t}\right)_{\text {p.n. }}}{\left.\frac{d M}{d t}\right)_{f, b \cdot L}}=\frac{(h \Delta T)_{\text {p.n. }}}{\left(h_{2} \Delta T\right)_{f \cdot b \cdot L}}\left(\frac{\lambda^{*}}{\lambda}\right)=\frac{(0.9)(16)}{(0.016)(40)} \frac{3}{2}=37.5
$$


and a reasonable lower limit becomes

$$
\frac{\left(\frac{d M}{d t}\right)_{p_{0} n_{0}}}{0.013}=7
$$

while the vapor generation rate for film boiling increases with increased $\Delta \mathrm{T}$, for our example, it is still about an order of magnitude less than the peak-nucleate rate. In addition, the generation-rate in film boiling is quite uniform when compared to the sporadic nature of nucleate boiling.

\section{CONCLUSIONS}

Theoretical expressions for the heat transfer coefficient between a liquid drop floating in film boiling on a cryogenic fluid were derived from the fundamental equations of momentum and energy. The expression for the heat transfer coefficient and the quasi-steady freezing analysis lead to a reasonable prediction of the time necessary for a drop at room temperature to freeze when placed on the cryogenic fluid. Further analysis of the freezing process (which is quite complex) and instrumented spheres is required.

The heat transfer coefficient to a sphere floating on the surface in film boiling can be shown to be equal to

$$
\mathrm{h}_{\mathrm{d}}=\frac{\mathrm{k}}{\mathrm{R}}+\left[\frac{2}{9} \frac{\mathrm{k}^{3} \mathrm{~g} \rho_{\mathrm{d}} \rho^{\lambda *}}{\mathrm{R} \mu\left(\mathrm{T}_{\mathrm{d}}-\mathrm{T}_{\mathrm{S}}\right)\left(\cos ^{2} \theta^{*}-2 \cos \theta^{*}+1\right)}\right]^{1 / 4}
$$

The value of $\theta^{*}$ may be approximated using figure 4 , for optimum levi- 
tated spheres. ${ }^{*}$ Non-optimum sphere estimates of $\theta^{*}$ can be calculated using the technique of appendix $\mathrm{B}$.

Two separate and distinct transitions are seen in the film boiling of a room temperature liquid drop on a cryogenic surface. First, the drop cools from room temperature and freezes. For water drops containing a blue dye, this freezing process becomes visible to the eye by a very noticeable change in the dye color. Secondly, when the drop temperature cools to the Leidenf rost point the supporting vapor layer is destroyed and the drop falls beneath the surface.

A motion picture supplement is available from the authors upon request.

*The "heaviest" sphere that can be floated on a given fluid. 


\section{APPENDIX A}

\section{SYMBOLS}

A

$\mathrm{B}_{\mathrm{o}}$

$\mathrm{C}_{\text {ice }}$

$\mathrm{C}_{\mathrm{p}}$

$\mathrm{C}_{\mathrm{p}, \mathrm{d}}$

$f\left(\theta^{*}\right)$

g

$\mathrm{g}_{\mathrm{c}}$

$\mathrm{h}$

$\mathrm{h}_{\mathrm{I}}$

$\mathrm{k}$

L

$\mathrm{M}$

$\mathrm{m}$

$\mathrm{m}_{\mathrm{d}}$

$P$

$\mathrm{P}_{\mathrm{o}}$

R

r

$\mathrm{T}$

$\mathrm{T}_{\mathrm{d}}$

$\mathrm{T}_{\text {do }}$

$\mathrm{T}_{\mathrm{f}}$

surface area of drop, $\mathrm{cm}^{2}$

Bond number, $\left[\left(\rho_{l}-\rho\right) \mathrm{gR}^{2}\right] / \sigma \mathrm{g}_{\mathrm{c}}$

specific heat of ice, joule $/(\mathrm{g})(\mathrm{K})$

specific heat at constant pressure, joule $/(\mathrm{g})(\mathrm{K})$

specific heat at constant pressure of drop, joule $/(\mathrm{g})(\mathrm{K})$

function, $\left(1-2 \cos \theta^{*}+\cos ^{2} \theta^{*}\right)$

local acceleration of gravity, $\mathrm{cm} / \mathrm{sec}^{2}$

gravitational constant in Newton's law of motion, $1 \frac{(\mathrm{g})(\mathrm{cm})}{(\text { dyne })\left(\mathrm{sec}^{2}\right)}$

heat transfer coefficient to drop, $\mathrm{W} /\left(\mathrm{cm}^{2}\right)(\mathrm{K})$

heat transfer coefficient to the interface, joule $/(\mathrm{sec})\left(\mathrm{cm}^{2}\right)$

thermal conductivity, joule $/(\mathrm{sec})(\mathrm{cm})(\mathrm{K})$

reference length, $\sqrt{\sigma \mathrm{g}_{\mathrm{c}} /\left[\left(\rho_{l}-\rho\right) \mathrm{g}\right]}, \mathrm{cm}$

mass, $\mathrm{g}$

dimensionless mass $\times$ time, $M / 4 \pi R \mu S$, sec

mass of water drop, $\mathrm{g}$

pressure, dyne $/ \mathrm{cm}^{2}$

atmospheric pressure, dyne $/ \mathrm{cm}^{2}$

radius of drop, $\mathrm{cm}$

radial coordinate, $\mathrm{cm}$

temperature, $\mathrm{K}$

drop temperature, $\mathrm{K}$

initial drop temperature, $K$

film temperature, $\left(\mathrm{T}_{\mathrm{d}}+\mathrm{T}_{\mathrm{S}}\right) / 2, \mathrm{~K}$ 


$$
\begin{aligned}
& \mathrm{T}_{\text {ice }} \quad \text { freezing temperature, } \mathrm{K} \\
& \mathrm{T}_{\mathrm{L}} \quad \text { Leidenf rost temperature, } \mathrm{K} \\
& T_{L, s t} \quad \text { Leidenfrost temperature of steel, } \bar{K} \\
& \mathrm{~T}_{\mathrm{S}} \quad \text { saturation temperature of liquid, } \mathrm{K}
\end{aligned}
$$

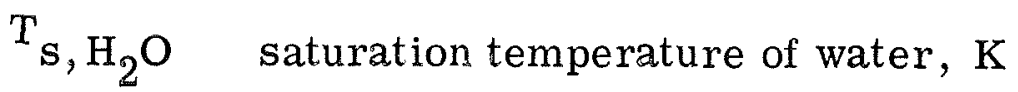

$$
\begin{aligned}
& \text { t time, sec } \\
& t_{i c e} \quad \text { time for heat of fusion to be removed from the drop, sec } \\
& t_{\text {sen }} \\
& \mathrm{V} \quad \text { volume of drop, } \mathrm{cm}^{3} \\
& \mathrm{~V}_{\mathrm{r}} \quad \text { radial velocity component, } \mathrm{cm} / \mathrm{sec} \\
& \mathrm{V}_{\theta} \quad \text { theta velocity component, } \mathrm{radian} / \mathrm{sec} \\
& \mathrm{v} \quad \text { volume, } \mathrm{cm}^{3} \\
& \mathrm{w}_{\mathrm{d}} \quad \text { weight of drop, dyne } \\
& \mathrm{X} \text { horizontal coordinate, } \mathrm{cm} \\
& \mathrm{Z} \quad \text { vertical coordinate, } \mathrm{cm} \\
& \mathrm{Z}_{\mathrm{o}} \quad \text { initial pressure head, } \mathrm{cm}, \mathrm{fig}, 3 \\
& \beta \quad 1 /\left(\mathrm{k} \rho_{\mathrm{m}} \mathrm{C}_{\mathrm{p}}\right),\left[\left(\mathrm{cm}^{2}\right)(\mathrm{K}) / \text { joule }\right]^{2} \mathrm{sec} \\
& \beta_{\text {ice }} \quad \beta \text { evaluated for ice properties, }\left[\left(\mathrm{cm}^{2}\right)(\mathrm{K}) / \mathrm{W}\right]^{2} \mathrm{sec}^{-1} \\
& \beta_{\text {st }} \quad \beta \text { evaluated for stainless steel properties, }\left[\left(\mathrm{cm}^{2}\right)(\mathrm{K}) / \mathrm{W}\right]^{2} \mathrm{sec}^{-1} \\
& \gamma \quad \text { latent heat of fusion, joule/g } \\
& \delta \quad \text { gap thickness, } \mathrm{cm} \\
& \Theta_{\mathrm{L}} \quad\left(\mathrm{T}_{\mathrm{L}}-\mathrm{T}_{\mathrm{S}}\right) /\left(\mathrm{T}_{\mathrm{L}, \mathrm{st}}-\mathrm{T}_{\mathrm{s}, \mathrm{H}_{2} \mathrm{O}}\right) \\
& \theta \text { angular coordinate, radians } \\
& \theta * \quad \text { defined in fig. } 1 \text {, radians }
\end{aligned}
$$


$\lambda$

$\lambda *$

$\mu$

$\nu$

$\rho$

$\rho_{\mathrm{d}}$

$\rho_{\text {ice }}$

$\rho_{\imath}$

$\rho_{\mathrm{m}}$

$\sigma$

$\tau_{\mathrm{r} \theta}, \tau_{\mathrm{rr}}$

$\tau$

$\Phi$ latent heat of vaporization, joule/g

modified latent heat of vaporization, joule/g

dynamic viscosity, $\mathrm{g} /(\mathrm{cm})(\mathrm{sec})=($ poise $)$

kinematic viscosity, $\mathrm{cm}^{2} / \mathrm{sec}$

density of vapor, $\mathrm{g} / \mathrm{cm}^{3}$

density of drop, $\mathrm{g} / \mathrm{cm}^{3}$

density of ice, $\mathrm{g} / \mathrm{cm}^{3}$

density of liquid, $\mathrm{g} / \mathrm{cm}^{3}$

density of metal, $\mathrm{g} / \mathrm{cm}^{3}$

surface tension, dyne $/ \mathrm{cm}$

shear stresses, see fig. 2 , and ref. 3 , dyne $/ \mathrm{cm}^{2}$

time, $\tau=\mathrm{t}-\left(\mathrm{t}_{\text {sen }}-\mathrm{t}_{\mathrm{ice}}\right)$

angular coordinate, see fig。1, radians 
APPENDIX B

\section{SOLUTION OF THE GOVERNING EQUATIONS}

\section{Momentum Equations}

The governing equations are made nondimensional to generalize the solution by selecting the following parameters

$$
\begin{gathered}
\zeta=\frac{\mathrm{r}}{\mathrm{R}} \\
\mathrm{v}_{\zeta}=\frac{\mathrm{v}_{\mathrm{r}}}{\mathrm{u}^{*}} \\
\mathrm{v}_{\theta}=\frac{\mathrm{v}_{\theta}}{\mathrm{u}^{*}} \\
\mathrm{Re}=\frac{\rho \mathrm{u} * \mathrm{R}}{\mu} \equiv \frac{\mathrm{\nu}}{\mathrm{R}} \\
\mathrm{p}=\frac{\mathrm{P}}{\frac{\rho \mathrm{u}^{2}}{\mathrm{~g}_{\mathrm{c}}}} \\
\mathrm{w}^{*}=\frac{\rho \mathrm{u}^{*} \mathrm{R}^{2}}{\mathrm{~g}_{\mathrm{c}}} \\
\mathrm{W}_{\mathrm{d}}=\frac{\frac{4}{3}}{\pi \rho_{\mathrm{d}} \mathrm{R}^{3}} \frac{\mathrm{g}}{\mathrm{g}_{\mathrm{c}}}
\end{gathered}
$$




$$
\begin{gathered}
S=\frac{1}{\operatorname{Pr}}\left[\frac{\mathrm{C}_{\mathrm{p}}\left(\mathrm{T}_{\mathrm{d}}-\mathrm{T}_{\mathrm{S}}\right)}{\lambda^{*}}\right] \\
\operatorname{Pr}=\frac{\mu \mathrm{C}_{\mathrm{p}}}{\mathrm{k}} \quad \text { Prandtl number } \\
\mathrm{Ra}^{*}=\frac{\rho\left(\rho_{l}-\rho\right) \mathrm{gR}^{3}}{\mu^{2} \mathrm{~S}} \quad \text { modified Rayleigh number }
\end{gathered}
$$

Nondimensionalizing the momentum equations (3) and (4) using (B1) through (B6) and introducing the stream function for spherical coordinates (ref. 3, p. 131) equations (3) and (4) can be reduced to

$$
E^{4}(\psi)=0
$$

where

$$
E^{2}=\frac{\partial^{2}}{\partial \zeta^{2}}+\frac{\sin \theta}{\zeta^{2}} \frac{\partial}{\partial \theta}\left(\frac{1}{\sin \theta} \frac{\partial}{\partial \theta}\right)
$$

The similarity transform

$$
\psi(\zeta, \theta)=\mathbf{F}(\zeta)(1-\cos \theta)
$$

is used to convert equation (A12) into the ordinary differential equation:

$$
F^{4}(\zeta)=0
$$

This is a linear homogeneous equation of fourth order which has a solution 


$$
F(\zeta)=C_{1}+C_{2} \zeta+C_{3} \zeta^{2}+C_{4} \zeta^{3}
$$

Therefore, the velocity components may be written as

$$
\begin{gathered}
\mathrm{V}_{\zeta}=-\frac{\mathrm{F}(\zeta)}{\zeta^{2}} \\
\mathrm{v}_{\theta}=\frac{F^{\prime}(\zeta) \tan \frac{\theta}{2}}{\zeta}
\end{gathered}
$$

Applying the boundary conditions (eqs. (8) to (10)), and using equations (B16) to (B18), allows the four constants to be expressed in terms of one constant of integration

$$
\begin{gathered}
\mathrm{C}_{1}=\frac{\mathrm{C}_{4}}{2}(1-3 \varphi) \\
\mathrm{C}_{2}=3 \mathrm{C}_{4} \varphi \\
\mathrm{C}_{3}=\frac{-3 \mathrm{C}_{4}}{2}(1+\varphi)
\end{gathered}
$$

where

$$
\varphi=1+\Delta=1+\frac{\delta}{R}
$$

The pressure distribution in the vapor gas is found by substituting equations (B17) and (B18) into the nondimensional form of equations (3) and (4) and solving for pressure. 


$$
\frac{\mathrm{p}(\zeta, \theta)}{\mathrm{C}_{4}}=\frac{-3(1+\varphi)}{\zeta}-6 \ln \zeta+12 \ln \left(\sec \frac{\theta}{2}\right)+\frac{{ }^{3} \mathrm{C}}{\mathrm{C}_{4}}
$$

The constants $\mathrm{C}_{4}$ and ${ }^{3} \mathrm{C}$ can now be determined from the static force balance, equation (12), and the boundary condition, equation (11),

$$
(\rho, \theta) \rightarrow(1, \theta *) \quad \text { then } \mathrm{p}-\mathrm{p}_{\mathrm{o}}
$$

Applying condition (B24) to equation (B23) gives

$$
\frac{{ }^{3} \mathrm{C}}{\mathrm{C}_{4}}=\frac{\mathrm{p}_{\mathrm{o}}}{\mathrm{C}_{4}}+3(1+\varphi)-12 \ln \left(\sec \frac{\theta^{*}}{2}\right)
$$

The remaining constant $C_{4}$ may now be determined from equation (12), using equations (B7), (B8), (B15) to (B20), and (B25).

$$
\mathrm{C}_{4}=-\frac{\frac{\mathrm{W}_{\mathrm{d}}}{3 \pi \mathrm{W}^{*}}}{\left(\cos ^{2} \theta^{*}-2 \cos \theta^{*}+1\right) \varphi}
$$

Therefore, utilizing $\mathrm{C}_{1}, \mathrm{C}_{2}, \mathrm{C}_{3}$, and $\mathrm{C}_{4}$, the velocity and pressure distributions are known functions of $\varphi$ where $\varphi=1+\Delta$ 。

Next, the energy equation is considered. Afterwards, the solution to the energy and momentum equations are combined in the interface energy balance to obtain a solution for the heat-transfer coefficient.

\section{ENERGY EQUATION}

The solution of the energy equation (6) is 


$$
\Theta=\frac{\varphi}{\Delta}\left(1-\frac{1}{\zeta}\right)
$$

The temperature gradient at each surface becomes

$$
\begin{gathered}
\left.\frac{\partial \Theta}{\partial \zeta}\right|_{\zeta=1}=\frac{\varphi}{\Delta} \\
\left.\frac{\partial \Theta}{\partial \zeta}\right|_{\zeta=\varphi}=\frac{1}{\Delta \varphi}
\end{gathered}
$$

\section{INTERFACE ENERGY BALANCE}

The velocity and temperature distributions are now expressed in terms of two unknowns, $\Delta$ and $\theta^{*}$. The interface energy balance is used to determine $\Delta$ in terms of $\theta^{*}$ 。

Substituting the values of constants $C_{1}$ to $C_{3}$ from equations (B19) to (B21) into equation (B17) and evaluating $v_{\zeta}$ at $\varphi$ gives the interface velocity

$$
\frac{\mathrm{v}_{\varphi}}{\mathrm{C}_{4}}=-\frac{1}{2}\left(\frac{1-3 \varphi}{\varphi^{2}}+3-\varphi\right)
$$

where $\mathrm{C}_{4}$ is a function of $\theta^{*}, \varphi$, and the parameter $\mathrm{W}_{\mathrm{d}} / \mathrm{w}^{*}$ (see eq. (B26)).

Nondimensionalizing equation (13) of the text, the nondimensional interface energy balance becomes

$$
\mathrm{v}_{\varphi}=-\left.\mathrm{S} \frac{\partial \Theta}{\partial \zeta}\right|_{\zeta=\varphi}
$$


where

$$
\mathrm{S}=\frac{1}{\operatorname{Pr}}\left[\frac{\mathrm{C}_{\mathrm{p}}\left(\overline{\mathrm{T}}_{\mathrm{d}}-\mathrm{T}_{\mathrm{s}}\right)}{\lambda^{*}}\right]
$$

and $\lambda$ has been replaced by $\lambda *$ to accommodate some effects of convection. Substituting equations (B26), (B29), and (B30) into (B31) gives (for $\Delta<<1)$

$$
\Delta^{4}=\left(\frac{6 \pi \mathrm{w}^{*} \mathrm{~S}}{\mathrm{~W}_{\mathrm{d}}}\right)\left(\cos ^{2} \theta^{*}-2 \cos \theta^{*}+1\right)
$$

The problem is now reduced to finding the value of $\theta^{*}$ from the balance of forces on the interface.

\section{FORCES ON THE INTERFACE}

Within the supporting liquid, there are two forces to be considered, buoyancy and surface tension. Buoyancy is composed of two terms: (a) fluid displacement by the sphere to an angle of $\theta^{*}$ and (b) fluid head as a result of fluid displacement by surface curvature. We now consider each of these forces separately.

Surface tension support. - If a load is placed on an axisymmetric shell or membrane structure, it is supported at the circular interface or load circle. Here the effective load is supported by a component of surface tension

$$
F_{\sigma}=2 \pi R \sigma \sin ^{2} \theta^{*}
$$


which may also be found by simply integrating the lift component of the surface tension pressure rise over the shell (i.e.,

$$
F_{\sigma}=\int_{0}^{2 \pi} \int_{0}^{\theta^{*}}\left(\frac{2 \sigma}{R}\right) R^{2} \cos \theta \sin \theta d \theta d \Phi
$$

Fluid displacement by the sphere. - The "pressure forces" acting on the spherical interface are illustrated in figure 3. The buoyancy resulting from these forces is obtained by integration; however, one must note that $\theta^{*}$ and $\mathrm{Z}_{0}$, while constants, are also unknown and must be determined from the force balance and interface curvature.

$\mathrm{F}_{\mathrm{B}}=\int_{0}^{2 \pi} \int_{0}^{\theta^{*}} \mathrm{P}_{l} \cos \theta \mathrm{dA_{1 }}-\int_{0}^{2 \pi} \int_{0}^{\pi-\theta^{*}} \mathrm{P}_{\mathrm{V}} \cos \theta \mathrm{dA} 2$

Integrating equation (B37) gives the buoyancy in terms of $\theta^{*}$ and $\mathrm{Z}_{\mathrm{o}}$ as:

$\mathrm{F}_{\mathrm{B}}=\pi\left(\rho_{l}-\rho\right) \frac{\mathrm{g}}{\mathrm{g}_{\mathrm{c}}} \mathrm{R}^{2}\left\{2 \mathrm{R}\left[\frac{\left(\rho_{l}+\rho\right)}{3\left(\rho_{l}-\rho\right)}-\frac{\cos \theta^{*}}{2}+\frac{\cos ^{3} \theta^{*}}{6}\right]+\mathrm{Z}_{\mathrm{o}}\left(1-\cos ^{2} \theta^{*}\right)\right\}$

Fluid displacement by interface curvature. - As $\theta$ increases beyond $\theta^{*}$, the free surface is determined by solving the Young-Laplace capillary equation.

$$
D_{x} u=-\frac{u}{x}-z
$$




$$
\mathrm{D}_{\mathrm{x}} \mathrm{z}=\tan \varphi \Rightarrow \frac{\mathrm{u}}{ \pm \sqrt{1-\mathrm{u}^{2}}}
$$

where

and

$$
\left.\begin{array}{c}
u=\sin \varphi \\
z=\frac{z}{L} \\
x=\frac{x}{L}
\end{array}\right\}
$$

where $\mathrm{X}$ is the horizontal coordinate.

For $\theta^{*}>\pi / 2, \tan \varphi>0$ and the $+\operatorname{sign}$ in equation (B39) is used; for $\theta^{*}<\pi / 2, \tan \varphi<0$ and the sign in equation (B39) is negative. A fourth order Runga-Kutta routine was applied to equations (B38) and (B39) and values of $\theta^{*}$ and $z_{0}$ were determined for the case

$$
\begin{gathered}
\mathrm{R}=0.3 \mathrm{~cm} \\
\rho_{l}-\rho=0.8 \mathrm{~g} / \mathrm{cc} \\
\rho_{\mathrm{S}}=1.0 \mathrm{~g} / \mathrm{cc} \\
\sigma=8.8 \text { dyne } / \mathrm{cm}
\end{gathered}
$$

which is shown as figure 7. While the forces are balanced to less than 0.3 percent, the exact solution was not obtained. For an exact solution, see reference 10 . In this case $\theta^{*}$ is approximately $113 \frac{1}{2}^{\circ}(\sim 1.98 \mathrm{rad})$ and the initial head is approximately 0.148 centimeter. 
A curve of $\theta^{*}$ as a function of Bond number is given as figure 4 , and can be used for approximating the value of $\theta^{*}$ for the most dense (heaviest) levitated sphere.

\section{HEAT TRANSFER COEFFICIENT \\ Drop Surface}

The Nusselt number for the sphere is given by

$$
\frac{\mathrm{h}_{\mathrm{d}} \mathrm{R}}{\mathrm{k}}=\left.\frac{\partial \Theta}{\partial \zeta}\right|_{\zeta=1}
$$

Substituting equations (B28) and (B33) into equation (B41) gives (assuming $\Delta<<1)$

$$
\frac{\mathrm{h}_{\mathrm{d}} \mathrm{R}}{\mathrm{k}}=1+\left[\frac{\mathrm{W}_{\mathrm{d}}}{6 \pi \mathrm{w} * \mathrm{~S}\left(\cos ^{2} \theta^{*}-2 \cos \theta^{*}+1\right)}\right]^{1 / 4}
$$

Liquid Interface

The Nusselt number at the interface

$$
\frac{\mathrm{h}_{\mathrm{I}} \mathrm{R}}{\mathbf{k}}=\left.\frac{\partial \Theta}{\partial \zeta}\right|_{\zeta=\varphi} \approx-1+\frac{1}{\Delta}
$$

Substituting equations (B24) and (B33) into equation (B43) gives

$$
\frac{\mathrm{h}_{\mathrm{I}} \mathrm{R}}{\mathrm{k}} \cong-1+\frac{1}{\Delta}=-1+\left[\frac{\mathrm{W}_{\mathrm{d}}}{6 \pi \mathrm{w}^{*} \mathrm{~S}\left(\cos ^{2} \xi^{*}-2 \cos \xi^{*}+1\right)}\right]^{1 / 4}
$$


Nondimensional Forms

It can be shown that nondimensional forms identify the basic terms governing the solution. The parameter $\mathrm{W}_{\mathrm{d}} / \mathrm{w}^{*} \mathrm{~S}$ can be expressed as

$$
\frac{\mathrm{W}_{\mathrm{d}}}{\mathrm{w}^{* \mathrm{~S}}}=\frac{4 \pi}{3} \mathrm{R}_{\mathrm{a}} \frac{\rho_{\mathrm{d}}}{\rho_{l}-\rho}
$$

Substituting equation (B45) into equations (B44) and (B42) indicates that heat transfer is influenced by the usual $R_{a}^{1 / 4}$ and the interrelation between the density ratio $\left[\rho_{\mathrm{d}} /\left(\rho_{l}-\rho\right)\right], \theta^{*}$ and Bond number.

$$
\begin{aligned}
& \frac{\mathrm{h}_{\mathrm{d}} \mathrm{R}}{\mathrm{k}}=1+\left[\frac{2}{9} \mathrm{R}_{\mathrm{a}}^{\mathrm{i}}\left(\frac{\rho_{\mathrm{d}}}{\rho_{l}-\rho}\right) \frac{1}{\mathrm{f}\left(\theta^{*}\right)}\right]^{1 / 4} \\
& \frac{\mathrm{h}_{\mathrm{I}} \mathrm{R}}{\mathrm{k}}=-1+\left[\frac{2}{9} \mathrm{R}_{\mathrm{a}}\left(\frac{\rho_{\mathrm{d}}}{\rho_{l}-\rho}\right) \frac{1}{\mathrm{f}\left(\theta^{*}\right)}\right]^{1 / 4}
\end{aligned}
$$

where

$$
f\left(\theta^{*}\right)=\cos ^{2} \theta^{*}-2 \cos \theta^{*}+1
$$




\section{REFERENCES}

1. Anon.: Propellant Work Shows New Film-Boiling Aspect. Chem. Eng. News, vol. 44, no. 17, Apr. 25, 1966, pp. 58, 61.

2. Baumeister, Kenneth J.; and Hamill, Thomas D.: Creeping Flow Solution of the Leidenfrost Phenomenon. NASA TN D-3133, 1965.

3. Bird, R. Byron,: Stewart, Warren E.; and Lightfoot, Edwin N.: Transport Phenomena. John Wiley \& Sons, Inc., 1960, p. 86.

4. Hendricks, Robert C.; and Baumeister, Kenneth J.: Heat Transfer and Leivtation of a Sphere in Leidenfrost Boiling, Proposed NASA Technical Note.

5. Hendricks, R. C.; Ohm, S. A.: Critical Levitation Locii for Spheres - Proposed NASA TM X.

6. Baumeister, Kenneth J.; Hendricks, Robert C.; and Hamill, Thomas D. : Metastable Leidenfrost States. NASA TN D-3226, 1966.

7. Dumo, Maurizio; Farello, G. E.; and Ferrari, Giuseppe: Notes on Droplet Heat Transfer - Chem. Eng. Progr. Sympo Ser., vol. 65, no. 92,1969 , pp. 175-187.

8. Keshock, E. G. ; and Bell, K. J. : Heat Transfer Coefficient Measurement of Liquid Nitrogen Drops Undergoing Film Boiling, paper presented at 1969 Cryogenic Engineering Conference, Los Angeles, California.

9. Merte, H.; and Clark, J. A.: Boiling Heat-Transfer Data for Liquid Nitrogen at Standard and Near-Zero Gravity. Advances in Cryogenic Engineering, K. D. Timmerhaus, ed., vol. 7, 1962, pp. 546, 550. 
10. Huh, Chun; and Scriven, L. E.: Shapes of Axisymmetric Fluid Interfaces of Unbounded Extent. J. Colloid Interface Sci., vol. 30, no. 3, July 1969, pp. 323-337. 
TABLE II。 - FREEZING DATA ON SMALL SPHERICAL WATER DROPS FLOATING ON LIQUID NITROGEN

AT AMBIENT CONDITIONS

\begin{tabular}{|c|c|c|c|c|c|}
\hline $\begin{array}{c}\text { Volume of } \\
\text { drop, } \\
\mathrm{cm}^{3}\end{array}$ & $\begin{array}{c}\text { Radius } \\
\text { of } \\
\text { drop, } \\
\mathrm{cm}\end{array}$ & $\begin{array}{c}\text { Time for } \\
\text { dye } \\
\text { change } \\
\text { to become } \\
\text { visible, } \\
\text { sec }\end{array}$ & $\begin{array}{c}\text { Time for } \\
\text { drop to be } \\
\text { completely } \\
\text { frozen, } \\
\text { sec }\end{array}$ & $\begin{array}{c}\text { Time for } \\
\text { drop to } \\
\text { fall to } \\
\text { bottom, } \\
\text { sec }\end{array}$ & $\begin{array}{c}\text { Initial drop } \\
\text { temperature, } \\
\mathrm{K}\end{array}$ \\
\hline $\mathrm{a}_{0.09}$ & 0.278 & 7 & 16 & 27 & 298 \\
$\mathrm{a} .113$ & .3 & 8 & 17 & 23 & 298 \\
$\mathrm{a}_{.075}$ & .26 & 9 & 17 & 28 & 298 \\
.11 & .295 & 9 & 18 & 27 & 298 \\
\hline
\end{tabular}

${ }^{a_{\text {Measured parameter. }}}$ 


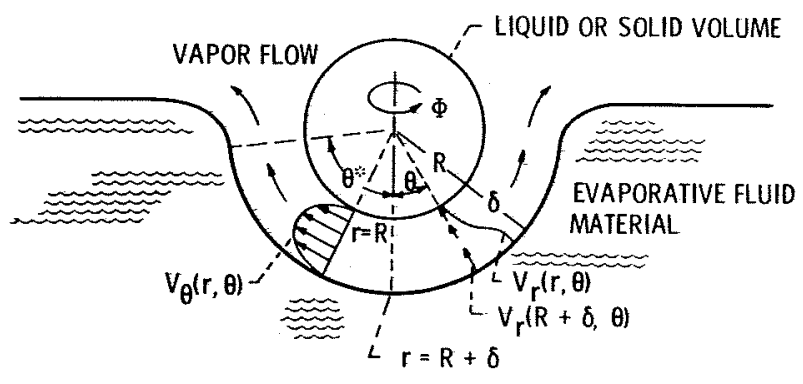

Figure 1. - Schematic model for evaporation from a spherical interface.

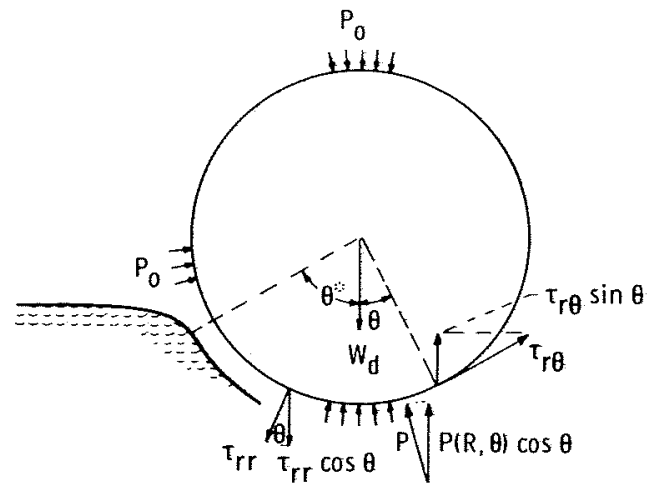

Figure 2. - Schematic of pressure and shear forces acting on the drop.

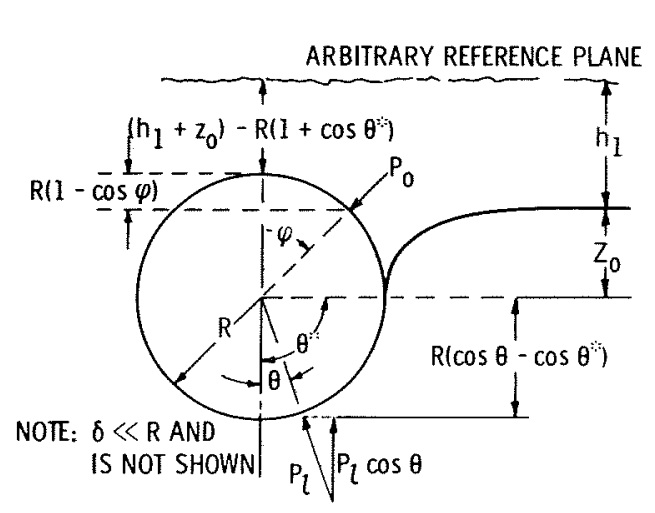

Figure 3. - Forces acting at the vapor-liquid interface. Fluid displacement by the sphere.

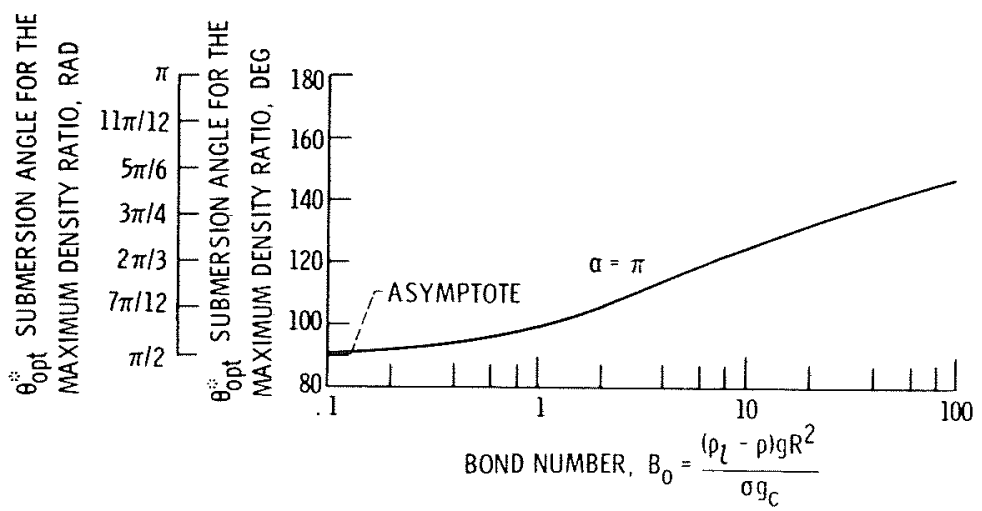

Figure 4. - Submersion angle $\theta_{0 \text { opt }}$ for the optimum density ratio. 


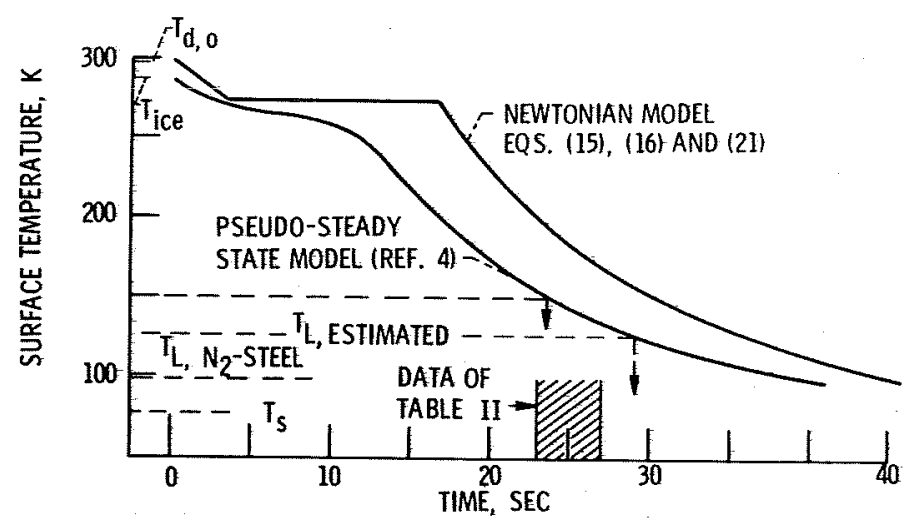

Figure 5. - Calculated surface temperature for a 0.61 centimeter diameter water sphere on liquid nitrogen as a function of time.

LEIDENFROST VALUES

$\triangle$ SATURATED WATER ON STAINLESS STEEL (REF. VALUE; $T_{1}$ St $^{-} T_{S}=73.5^{\circ} \mathrm{K}$ )

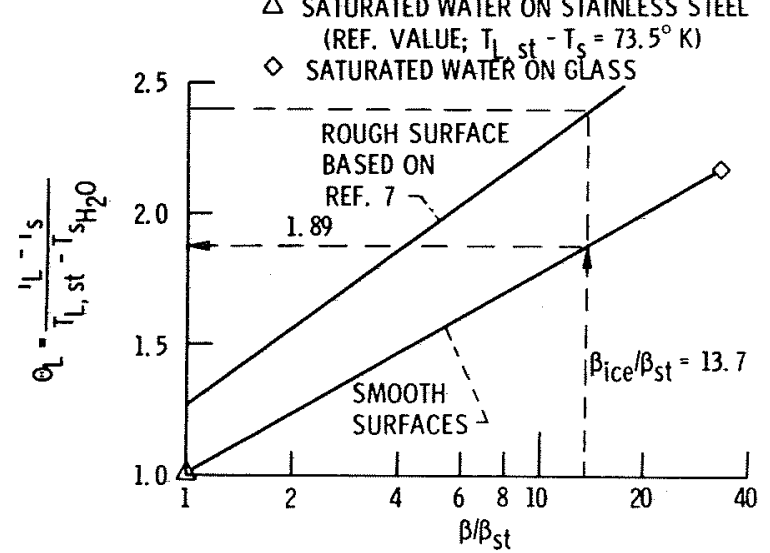

Figure 6. - Effect of surface on Leidenfrost temperature.

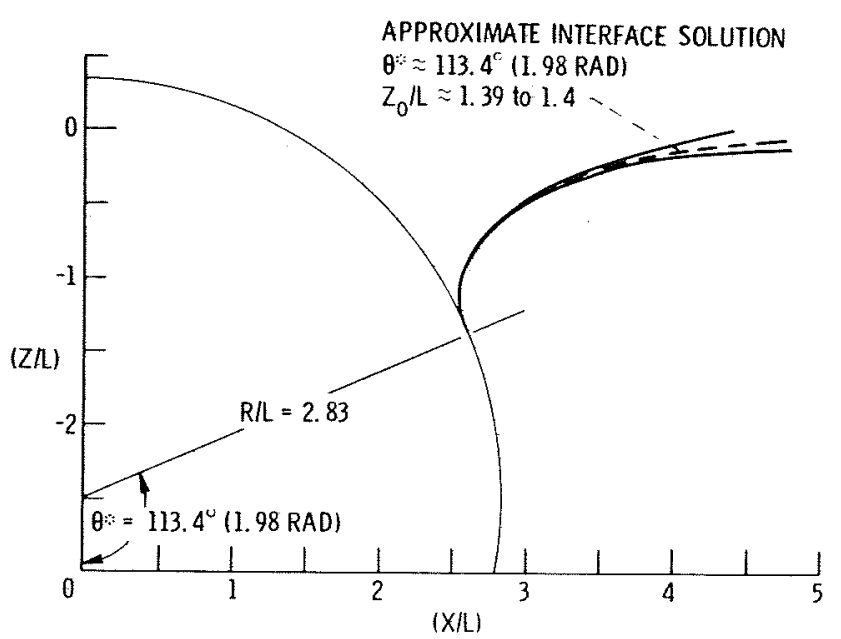

Figure 7. - Interface configuration for water sphere on liquid nitrogen. 